\section{CAMT-MPL: congenital amegakaryocytic thrombocytopenia caused by MPL mutations - heterogeneity of a monogenic disorder - a comprehensive analysis of 56 patients}

\author{
Manuela Germeshausen and Matthias Ballmaier
}

Central Research Facility Cell Sorting, Hannover Medical School, Hannover, Germany

\section{ABSTRACT}

C ongenital amegakaryocytic thrombocytopenia caused by deleterious homozygous or compound heterozygous mutations in MPL (CAMT-MPL) is a rare inherited bone marrow failure syndrome presenting as an isolated thrombocytopenia at birth progressing to pancytopenia due to exhaustion of hematopoietic progenitors. The analysis of samples and clinical data from a large cohort of 56 patients with CAMT-MPL resulted in a detailed description of the clinical picture and reliable genotype-phenotype correlations for this rare disease. We extended the spectrum of CAMT causing MPL mutations regarding number (17 novel mutations) and impact. Clinical courses showed great variability with respect to the severity of thrombocytopenia, the development of pancytopenia and the consequences from bleedings. The most severe clinical problems were (i) intracranial bleedings pre- and perinatally and the resulting long-term consequences, and (ii) the development of aplastic anemia in the later course of the disease. An important and new finding was that thrombocytopenia was not detected at birth in a quarter of the patients. The rate of non-hematological abnormalities in CAMT-MPL was higher than described so far. Most of the anomalies were related to the head region (brain anomalies, ocular and orbital anomalies) and consequences of intracranial bleedings. The present study demonstrates a higher variability of clinical courses than described so far and has important implications on diagnosis and therapy. The diagnosis CAMT-MPL has to be considered even for those patients who are inconspicuous in the first months of life or show somatic anomalies typical for other inherited bone marrow failure syndromes.

\section{Introduction}

Congenital amegakaryocytic thrombocytopenia (CAMT, MIM \#604498) is a rare inherited bone marrow failure syndrome (IBMFS) which usually presents as severe thrombocytopenia at birth without specific characteristics and progresses to aplastic anemia during the first years of life. ${ }^{1,2}$ Deleterious mutations in MPL coding for the thrombopoietin receptor have first been identified as single molecular cause of CAMT, ${ }^{3,4}$ but the disease is now regarded to be genetically heterogeneous. ${ }^{5}$ Indeed, mutations in the gene for thrombopoietin (THPO) have been recently described in some of these patients. ${ }^{6-8}$ Furthermore, newborns with other IBMFS like Dyskeratosis congenita, Fanconi anemia, MECOM associated syndrome or microdeletion syndromes can present phenotypically as CAMT since pathognomonic signs of these syndromes might be not yet apparent. ${ }^{9 \cdot 12}$ In the following we use the term CAMT-MPL for the IBMFS caused by biallelic mutations in MPL.

Previous descriptions of CAMT-MPL are based on single case reports or small case series, not allowing for a comprehensive evaluation of the phenotypic spectrum of the disease. ${ }^{1,2,13}$ Over the last 20 years we analyzed samples and clinical data from patients suspicious for inherited thrombocytopenia and could identify 56 patients with CAMT-MPL. The aims of our analysis of clinical, genetic and laboratory data are (i) a detailed description of the clinical picture of CAMT-MPL, (ii) the establishment of genotype-phenotype correlations allowing for the prediction
Haematologica 2021

Volume 106(9):2439-2448

\section{Correspondence:}

MANUELA GERMESHAUSEN

germeshausen.manuela@mh-hannover.de

MATTHIAS BALLMAIER

ballmaier.matthias@mh-hannover.de

Received: May s4, 2020.

Accepted: July 17, 2020.

Pre-published: July 23, 2020.

https://doi.org/10.3324/haematol.2020.257972

(C)2021 Ferrata Storti Foundation

Material published in Haematologica is covered by copyright. All rights are reserved to the Ferrata Storti Foundation. Use of published material is allowed under the following terms and conditions:

https://creativecommons.org/licenses/by-nc/4.0/legalcode. Copies of published material are allowed for personal or internal use. Sharing published material for non-commercial purposes is subject to the following conditions:

https://creativecommons.org/licenses/by-nc/4.0/legalcode, sect. 3. Reproducing and sharing published material for commercial purposes is not allowed without permission in writing from the publisher. 
of development of aplastic anemia and malignancies, and (iii) a better understanding of the thrombopoietin-MPL system in vivo.

\section{Methods}

\section{Patients}

Patient material and clinical data were provided after informed consent. The study was approved by the local ethics committee. Patients suspected to have CAMT were analyzed for mutations in MPL. Twenty-three of the 56 CAMT-MPL patients included in this study were part of earlier publications of our group, ${ }^{4,14,15}$ two were the subject of single case studies. ${ }^{16,17}$ Six further patients had an already known heterozygous MPL mutation and a seemingly unaffected second allele.

\section{Sequencing}

Mutational analyses were performed by Sanger sequencing from leukocyte derived genomic DNA as described previously. ${ }^{4}$

\section{In silico analysis of mutation data}

PROVEAN, ${ }^{18}$ SIFT, ${ }^{19}$ Polyphen $2,{ }^{20}$ and MutationTaster ${ }^{21}$ algorithms were used for prediction of the effect of MPL mutations on protein function. Putative splicing mutations were evaluated by BDGP splice site prediction, ${ }^{22}$ MaxEntScan algorithm, ${ }^{23}$ and Human Splicing Finder (HSF 3.1). ${ }^{24}$

\section{Flow cytometric analyses}

Flow cytometric analyses of CD110 expression on early hematopoietic progenitors were performed as described earlier. ${ }^{25}$

\section{Thrombopoietin levels}

Thrombopoietin serum or plasma levels were measured using a commercially available enzyme-linked immunosorbent assay (ELISA) kit (Quantikine, R\&D systems).

\section{Results}

\section{MPL mutations}

We identified 56 patients with homozygous $(\mathrm{n}=39)$ or compound heterozygous $(\mathrm{n}=17)$ mutations in $M P L$ (Tables 1; Online Supplementary Table S1). We detected 38 different mutations (Figure 1, Table 2), 17 out of them are novel (Tables 1 and 2; Online Supplementary Table S2).

Six different nonsense mutations (allele frequency $20 \%$; including three novel mutations) and three different frame shift deletions (allele frequency 13\%) affected 20 different patients (Table 2A and B; Online Supplementary Table S2).

Five different splice site mutations (allele frequency $10 \%$, two novel) affected 11 patients (ten families). With the exception of c. $391+5 \mathrm{G}>\mathrm{C}$, all are predicted to lead to a complete loss of function (Table 2C). Prediction was confirmed for c.79+2T $>$ A by measurement of missing CD110 surface expression on hematopoietic progenitors (Figure 2, see below) and for 213-1G>A and c.79+2T $>$ A by the severe course of the disease in the affected patients. In contrast, patients with the mutation c. $391+5 \mathrm{G}>\mathrm{C}$, allowing a residual natural splicing, ${ }^{26}$ had a less severe course and measurable CD110 expression on hematopoietic progenitors (Figure 2).

The majority of mutations in our patient cohort were missense mutations (24 different mutations in 35 patients, allele frequency $57 \%, 12$ novel, Table 2D) Two hotspots (amino acids 102-104: 18 alleles, 12 patients; proline residues 135-136: six alleles, five patients) account for $21 \%$ of all mutated alleles. Fifteen of 24 missense mutations are predicted to be deleterious by all applied algorithms, 23 of 24 by at least one of the algorithms (Table 2D).

Due to the small number of individual cases it is difficult to predict clinical courses from the individual missense mutations. Specifically severe courses were observed in patients affected from p.Arg102Pro, p.Trp154Arg, and p.Leu169His. The latter one was found in three unrelated patients from Chile suggesting a founder mutation with regional significance.

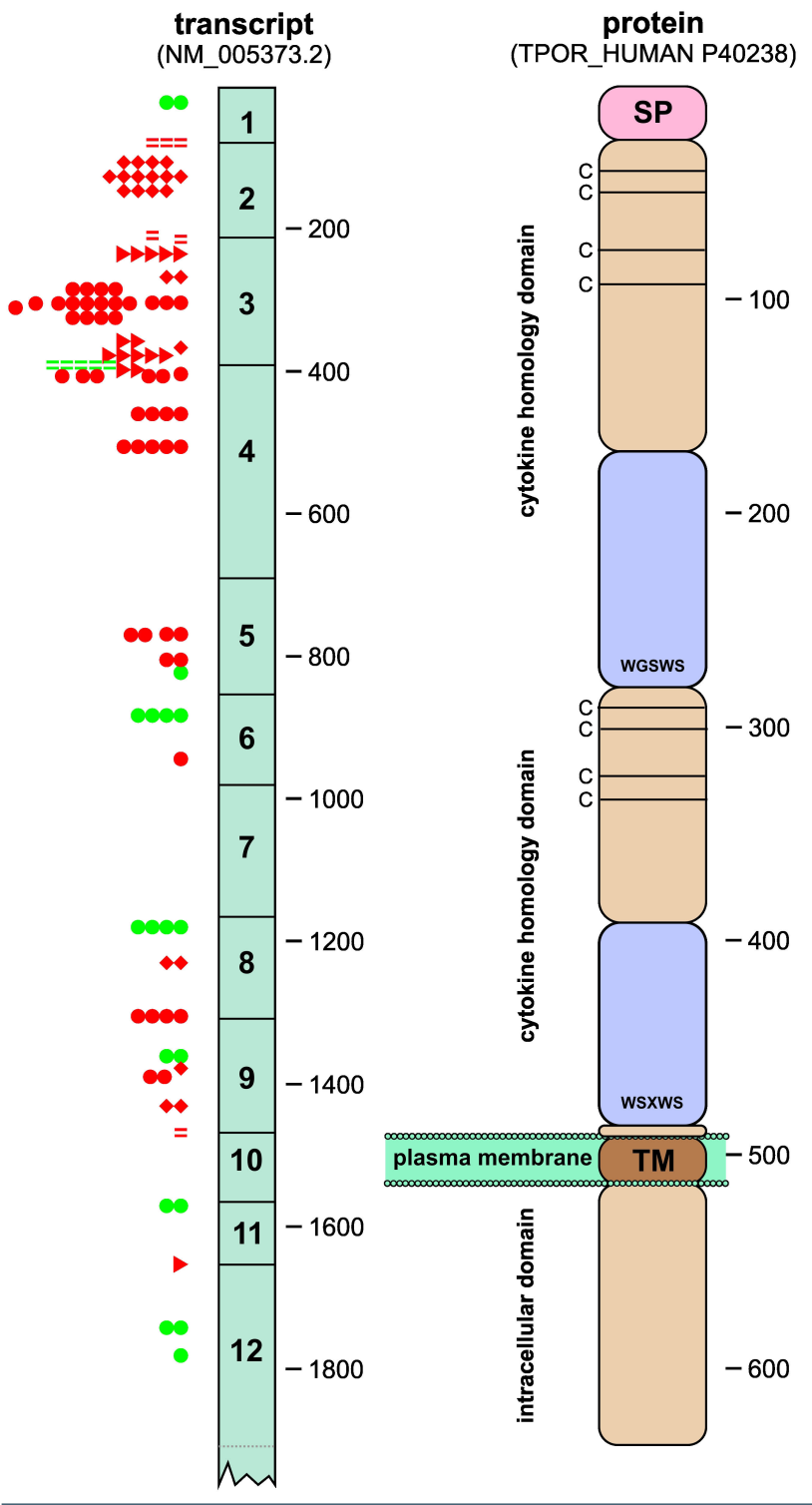

Figure 1. MPL alleles in CAMT patients All MPL mutations found in our cohort of congenital amegakaryocytic thrombocytopenia (CAMT) patients are depicted on the left side beneath the exon structure of the MPL transcript with corresponding numbering of bases (coding sequence). Every symbol represents a mutated allele in one patient. The derived protein structure with the functional domains of the receptor protein and corresponding numbering of amino acids is shown on the right. Circles: missense mutations; diamonds: nonsense mutations; triangles: frame shift deletions; equal signs: splice site mutations. Mutations with less severe phenotypes are marked in green color (see main text). SP: signal peptide, TM: transmembrane domain 
Less severe courses (thrombocytopenia not detected at birth or onset of pancytopenia not in early childhood) were observed in patients with mutations p.Met8Arg, p.Asp295Tyr, p.Pro394Ser and missense mutations in exons 11 and 12 affecting the intracytoplasmic part of the receptor molecule (p.Leu524Arg, p.Pro581Leu, p.Leu594Trp). p.Met8Arg is the most N-terminal mutation in MPL described so far. The mutation is located in the signal peptide region of the MPL precursor protein and might affect signaling of the molecule as well as the function of this codon as a possible alternative translation initiation site. It was homozygously found in a patient from consanguineous parents first diagnosed with thrombocytopenia at the age of 9 months.

The mutation p.Arg454Pro which is predicted to be benign by all applied prediction algorithms was homozy- gously found in a patient presenting at the age of 2 years with a profound isolated hypomegakaryocytic thrombocytopenia.

p.Arg102His is the third mutation affecting Arg102 in CAMT: p.Arg102Cys and p.Arg102Pro cause a severe phenotype of CAMT in patients ${ }^{15}$ and disturb intracellular trafficking of the MPL protein ${ }^{27}$ although p.Arg102His as well as p.Arg102Pro are predicted to be benign by SIFT and PROVEAN algorithms (Table 2D).

\footnotetext{
${ }^{*}$ The nomenclature of sequence variants follows the recommendations of the Human Genome Variation Society (HGVS). A discription at the DNA level is provided in the Online Supplementary Table S2. Missense mutations are described at protein level, other mutations on DNA level (coding sequence). Amino acid substitutions are deduced from DNA sequencing results, the recommended parentheses have been omitted for better readability.
}

Table 1. Congenital amegakaryocytic thrombocytopenia patients included in this study.

\begin{tabular}{|c|c|c|c|c|}
\hline patient ID & sex & intron/exon & CDS & protein \\
\hline CAMT001 & $\mathrm{f}$ & E2 & c. $127 \mathrm{C}>\mathrm{T}$ & p.Arg43Ter \\
\hline CAMT006 & $\mathrm{f}$ & E3 & c. $268 \mathrm{C}>\mathrm{T}$ & p.Arg90Ter \\
\hline CAMT007 & $\mathrm{m}$ & E3 & c. $305 \mathrm{G}>\mathrm{C}$ & p.Arg102Pro \\
\hline CAMT009 & $\mathrm{f}$ & E3 & c.378delT & p.Phe126LeufsTer5 \\
\hline \multirow[t]{2}{*}{ CAMT011 } & $\mathrm{f}$ & E5 & c. $.823 \mathrm{C}>\mathrm{A}$ & p.Pro275Thr \\
\hline & & E3 & c. $305 \mathrm{G}>\mathrm{C}$ & p.Arg102Pro \\
\hline CAMT012 & $\mathrm{m}$ & E3 & c. $305 \mathrm{G}>\mathrm{C}$ & p.Arg102Pro \\
\hline CAMT013 & $\mathrm{f}$ & E3 & c.235_236delCT & p.Leu79GlufsTer84 \\
\hline CAMT015 & $\mathrm{f}$ & E3 & c. $305 \mathrm{G}>\mathrm{C}$ & p.Arg102Pro \\
\hline CAMT017 & $\mathrm{f}$ & E2 & c. $127 \mathrm{C}>\mathrm{T}$ & p.Arg43Ter \\
\hline CAMT018 & $\mathrm{f}$ & E2 & c. $127 \mathrm{C}>\mathrm{T}$ & p.Arg43Ter \\
\hline CAMT019 & f & E2 & c. $127 \mathrm{C}>\mathrm{T}$ & p.Arg43Ter \\
\hline CAMT030 & $\mathrm{m}$ & Il & c. $79+2 \mathrm{~T}>\mathrm{A}$ & p.Asp27fs \\
\hline CAMT031 & $\mathrm{f}$ & E3 & c.378delT & p.Phe126LeufsTer5 \\
\hline CAMT033 & $\mathrm{f}$ & $\begin{array}{l}\text { E3 } \\
\text { I2 }\end{array}$ & $\begin{array}{c}\text { c.378delT } \\
\text { c.213-1G }>\text { A }\end{array}$ & $\begin{array}{c}\text { p.Phe126LeufsTer5 } \\
\text { splicing defect }\end{array}$ \\
\hline CAMT034 & $\mathrm{f}$ & E3 & c.378delT & p.Phe126LeufsTer5 \\
\hline CAMT036 & $\mathrm{m}$ & E2 & c. $127 \mathrm{C}>\mathrm{T}$ & p.Arg43Ter \\
\hline \multirow[t]{2}{*}{ CAMT039 } & $\mathrm{f}$ & E3 & c.378delT & p.Phe126LeufsTer5 \\
\hline & & E3 & c. $.367 \mathrm{C}>\mathrm{T}$ & p.Arg123Ter \\
\hline CAMT043 & $\mathrm{f}$ & E3 & c. $304 \mathrm{C}>\mathrm{T}$ & p.Arg102Cys \\
\hline CAMT050 & $\mathrm{f}$ & E4 & c. $460 \mathrm{~T}>\mathrm{C}$ & p.Trp154Arg \\
\hline CAMT052 & f & E8 & c. $1305 \mathrm{G}>\mathrm{C}$ & p.Trp435Cys \\
\hline CAMT055 & $\mathrm{m}$ & E5 & c.770G $>\mathrm{T}$ & p.Arg257Leu \\
\hline \multirow[t]{2}{*}{ CAMT058 } & $\mathrm{m}$ & E4 & c. $407 \mathrm{C}>\mathrm{T}$ & p.Prol36Leu \\
\hline & & E12 & c. $1781 \mathrm{~T}>\mathrm{G}$ & p.Leu594Trp \\
\hline CAMT059 & $\mathrm{m}$ & E8 & c. $1230 \mathrm{G}>\mathrm{A}$ & p.Trp410Ter \\
\hline CAMT067 & $\mathrm{m}$ & $\begin{array}{l}\text { E3 } \\
\text { E3 }\end{array}$ & $\begin{array}{l}\text { c. } 305 \mathrm{G}>\mathrm{C} \\
\text { c. } 311 \mathrm{~T}>\mathrm{C}\end{array}$ & $\begin{array}{l}\text { p.Arg102Pro } \\
\text { p.Phe104Ser }\end{array}$ \\
\hline CAMT075 & $\mathrm{m}$ & E3 & c. $305 \mathrm{G}>\mathrm{C}$ & p.Arg102Pro \\
\hline CAMT082 & $\mathrm{m}$ & $\begin{array}{l}\text { E3 } \\
\text { I3 }\end{array}$ & $\begin{array}{c}\text { c. } 305 \mathrm{G}>\mathrm{C} \\
\text { c. } 391+5 \mathrm{G}>\mathrm{C}\end{array}$ & $\begin{array}{c}\text { p.Arg102Pro } \\
\text { splicing defect }\end{array}$ \\
\hline CAMT083 & $\mathrm{m}$ & E8 & c. $1305 \mathrm{G}>\mathrm{C}$ & p.Trp435Cys \\
\hline CAMT087 & $\mathrm{m}$ & E2 & c. $127 \mathrm{C}>\mathrm{T}$ & p.Arg43Ter \\
\hline \multirow[t]{2}{*}{ CAMT092 } & $\mathrm{f}$ & $\mathrm{I} 3$ & c. $391+5 \mathrm{G}>\mathrm{C}$ & splicing defect \\
\hline & & E9 & c. $1378 \mathrm{C}>\mathrm{T}$ & p.Gln460Ter \\
\hline CAMT098 & $\mathrm{m}$ & $\begin{array}{l}\text { Il } \\
\text { E4 }\end{array}$ & $\begin{array}{l}\text { c. } 79+2 \mathrm{~T}>\mathrm{A} \\
\text { c. } 404 \mathrm{C}>\mathrm{G}\end{array}$ & $\begin{array}{c}\text { splicing defect } \\
\text { p.Prol35Arg }\end{array}$ \\
\hline
\end{tabular}

\begin{tabular}{|c|c|c|c|c|}
\hline patient ID & $\operatorname{sex}$ & intron/exon & CDS & protein \\
\hline CAMT101 & $\mathrm{m}$ & E6 & c. $883 \mathrm{G}>\mathrm{C}$ & p.Asp295Tyr \\
\hline CAMT102 & f & E6 & c. $883 \mathrm{G}>\mathrm{C}$ & p.Asp295Tyr \\
\hline \multirow[t]{2}{*}{ CAMT108 } & $\mathrm{f}$ & E3 & c.378delT & p.Phe126LeufsTer5 \\
\hline & & I11 & c.1653delG & p.Lys553ArgfsX75 \\
\hline \multirow[t]{2}{*}{ CAMT113 } & $\mathrm{f}$ & I2 & c. $212+1 \mathrm{G}>\mathrm{A}$ & splicing defect \\
\hline & & $\mathrm{I} 3$ & c. $391+5 \mathrm{G}>\mathrm{C}$ & splicing defect \\
\hline CAMT122 & $\mathrm{f}$ & E12 & c. $1742 \mathrm{C}>\mathrm{T}$ & p.Pro581Leu \\
\hline CAMT123 & $\mathrm{f}$ & E4 & c. $460 \mathrm{~T}>\mathrm{C}$ & p.Trp154Arg \\
\hline CAMT125 & $\mathrm{f}$ & E4 & c. $.407 \mathrm{C}>\mathrm{A}$ & p.Prol36His \\
\hline \multirow[t]{2}{*}{ CAMT130 } & $\mathrm{f}$ & I3 & c. $391+5 \mathrm{G}>\mathrm{C}$ & splicing defect \\
\hline & & E5 & c. $769 \mathrm{C}>\mathrm{T}$ & p.Arg257Cys \\
\hline CAMT133 & $\mathrm{f}$ & E8 & c. $1180 \mathrm{C}>\mathrm{T}$ & p.Pro394Ser \\
\hline CAMT136 & $\mathrm{m}$ & E9 & c. $1361 \mathrm{G}>\mathrm{C}$ & p.Arg454Pro \\
\hline CAMT137 & f & $\begin{array}{l}\text { I3 } \\
\text { E5 }\end{array}$ & $\begin{array}{c}\text { c. } 391+5 \mathrm{G}>\mathrm{C} \\
\text { c. } 769 \mathrm{C}>\mathrm{T}\end{array}$ & $\begin{array}{l}\text { splicing defect } \\
\text { p.Arg257Cys }\end{array}$ \\
\hline CAMT138 & $\mathrm{f}$ & E9 & c. $1390 \mathrm{~A}>\mathrm{G}$ & p.Arg464Gly \\
\hline CAMT140 & m & E8 & c. $1180 \mathrm{C}>\mathrm{T}$ & p.Pro394Ser \\
\hline \multirow[t]{2}{*}{ CAMT144 } & $\mathrm{f}$ & E3 & c. $304 \mathrm{C}>\mathrm{T}$ & p.Arg102Cys \\
\hline & & E4 & c. $.407 \mathrm{C}>\mathrm{T}$ & p.Pro136Leu \\
\hline CAMT157 & $\mathrm{m}$ & E4 & c. $506 \mathrm{~T}>\mathrm{A}$ & p.Leu169His \\
\hline CAMT159 & $\mathrm{f}$ & E1 & c. $23 \mathrm{~T}>\mathrm{G}$ & p.Met8Arg \\
\hline CAMT160 & $\mathrm{m}$ & E3 & c.235_236delCT & p.Leu79GlufsX84 \\
\hline CAMT163 & $\mathrm{f}$ & E9 & c. $1431 \mathrm{G}>\mathrm{A}$ & p.Trp477Ter \\
\hline CAMT167 & $\mathrm{f}$ & E5 & c. $805 \mathrm{~T}>\mathrm{C}$ & p.Trp269Arg \\
\hline CAMT168 & $\mathrm{m}$ & E11 & c. $1571 \mathrm{~T}>\mathrm{G}$ & p.Leu524Arg \\
\hline CAMT169 & $\mathrm{m}$ & $\begin{array}{l}\text { E3 } \\
\text { E3 }\end{array}$ & $\begin{array}{c}\text { c.305G >A } \\
\text { c.235_236delCT }\end{array}$ & $\begin{array}{c}\text { p.Arg102His } \\
\text { p.Leu79GlufsX84 }\end{array}$ \\
\hline \multirow[t]{2}{*}{ CAMT178 } & $\mathrm{f}$ & E3 & c. $.305 \mathrm{G}>\mathrm{C}$ & p.Arg102Pro \\
\hline & & E4 & c. $506 \mathrm{~T}>\mathrm{A}$ & p.Leul69His \\
\hline CAMT179 & f & $\begin{array}{l}\text { E4 } \\
\text { E6 }\end{array}$ & $\begin{array}{l}\text { c. } 407 \mathrm{C}>\mathrm{G} \\
\text { c. } 944 \mathrm{~T}>\mathrm{G}\end{array}$ & $\begin{array}{l}\text { p.Prol36Arg } \\
\text { p.Phe315Cys }\end{array}$ \\
\hline CAMT180 & $\mathrm{m}$ & E2 & c. $127 \mathrm{C}>\mathrm{T}$ & p.Arg43Ter \\
\hline CAMT181 & f & $\begin{array}{l}\text { E3 } \\
\text { I9 }\end{array}$ & $\begin{array}{c}\text { c. } 305 \mathrm{G}>\mathrm{C} \\
\text { c. } 1469-2 \mathrm{~A}>\mathrm{T}\end{array}$ & $\begin{array}{c}\text { p.Arg102Pro } \\
\text { splicing defect }\end{array}$ \\
\hline CAMT183 & $\mathrm{f}$ & E4 & c. $506 \mathrm{~T}>\mathrm{A}$ & p.Leu169His \\
\hline
\end{tabular}


CD110 expression on hematopoietic progenitors

We analyzed the expression of the MPL encoded protein $\mathrm{CD} 110$ on $\mathrm{CD} 34^{+} \mathrm{CD} 38^{\text {lo }}$ hematopoietic progenitors ${ }^{25}$ from 30 CAMT-MPL patients and eight healthy donors (Figure 2). There was a clear correlation between real CD110 expression and the predicted effects from the mutation analysis on the one hand and between CD110 expression and clinical course on the other hand: CD110 expression was not measurable on cells from patients with nonsense or frame shift mutations and mutations predicted to lead to a complete loss of a splice site (Figure 2 , group A). In the group of patients with missense mutations we observed more variation in CD110 surface expression (Figure 2, group B) which was correlated with clinical courses: the higher CD110 expression observed in two patients homozygously affected by p.Asp295Tyr (Figure 2, violet squares) was correlated with a less severe course (CAMT101 and CAMT102). Cells from the patient with the p.Arg454Pro mutation predicted to be benign showed a nearly normal surface expression of CD110 (Figure 2, green square). In contrast, in patients with the mutation p.Arg102Pro (homozygous or compound heterozygous with a null mutation) and a relative severe course we measured a very low CD110 signal (Figure 2, blue squares).

\section{Thrombopoietin plasma levels}

Plasma levels of thrombopoietin are inversely proportional to the total mass of functional MPL in the body due to a direct negative feedback loop. Healthy donors usually have thrombopoietin plasma levels below $30 \mathrm{pg} / \mathrm{mL}$ (range $<30-196 \mathrm{pg} / \mathrm{mL}$ ). In contrast, thrombopoietin plasma levels were markedly elevated in all samples from 40 patients in this study and ranged from 400 to $>4,000$ $\mathrm{pg} / \mathrm{mL}$ (median 1,493 pg/mL; Online Supplementary Table S1). Within the group of CAMT-MPL patients we did not find a significant correlation between THPO levels and either MPL expression levels on early hematopoietic progenitors or severity of the disease, but patients predicted to have a total receptor deficiency had a higher median thrombopoietin level (median 1,685 pg/mL, $\mathrm{n}=13$ ) compared to patients with mutations allowing for a residual activity of the receptor (median $1,472 \mathrm{pg} / \mathrm{mL}, \mathrm{n}=27$ ). In our study, the measurement of MPL expression on hematopoietic precursors was a better predictor of the clinical course than THPO levels. Unexpectedly low

Table 2. MPL mutations in congenital amegakaryocytic thrombocytopenia patients. All mutations found in our group of congenital amegakaryocytic thrombocytopenia (CAMT) patients are listed regarding their type in Tables $2 A$ to $D$ together with their predicted impact on the MPL protein and their incidence in our patient group (bold: novel mutations). $2 \mathrm{~A}$ (nonsense mutations) and 2B (frame shift mutations): prediction according to MutationTaster ${ }^{21}$ with probability; 2C (splice mutations): prediction according to BDGP splice site prediction, ${ }^{22}$ MaxEntScan algorithm (MaxEnt), ${ }^{23}$ and Human Splicing Finder (HSF). ${ }^{24}$ MDD: maximal dependency decomposition (only for donor sites), MM: Markov model (1st order), WMM: weighted matrix method. 2D (missense mutations): prediction according to MutationTaster, ${ }^{21}$ PROVEAN, ${ }^{18}$ and SIFT ${ }^{19}$ algorithms with the respective score values. ${ }^{*}$ The mutation previously referred to as c.1653+1delG (now c.1653delG) should be also regarded as a frame shift mutation since the predicted effect on the splice donor site is marginal (Table $2 \mathrm{C}$ ) and the effect on the protein is caused mainly by the frame shift. ${ }^{56}$

Table 2A. Nonsense mutations in congenital amegakaryocytic thrombocytopenia patients.

\begin{tabular}{lllll} 
CDS & Exon & protein & Mlutationlaster & incidence \\
c.127C $>$ T & E2 & p.Arg43Ter & disease causing $/ 1$ & ho: $n=7 ;$ het: $n=0$ \\
c.268C $>$ T & E3 & p.Arg90Ter & disease causing $/ 1$ & ho: $n=1 ;$ het: $n=0$ \\
\hline c.367C $>$ T & E3 & p.Arg123Ter & disease causing $/ 1$ & ho: $n=0 ;$ het: $n=1$ \\
c.1230G $>$ A & E8 & p.Trp410Ter & disease causing $/ 1$ & ho: $n=1 ;$ het: $n=0$ \\
\hline c. $1378 C>$ T & E9 & p.Gln460Ter & disease causing $/ 1$ & ho: $n=0 ;$ het: $n=1$ \\
c.1431G $>$ A & E9 & p.Trp477Ter & disease causing $/ 1$ & ho: $n=1 ;$ het: $n=0$ \\
\hline
\end{tabular}

CDS: coding DNA sequence; ho: homozygous individuals: het: heterozygous individuals.

Table 2B. Frame shift mutations in congenital amegakaryocytic thrombocytopenia patients.

\begin{tabular}{|c|c|c|c|c|}
\hline CDS & $5 \times 01$ & protein & MutationTaster & incidence \\
\hline c.235_236delCT & E3 & p.Leu79Glufs*84 & disease causing / 1 & ho: $n=2$; het: $n=1$ \\
\hline c.378delT & E3 & p.Phe126LeufsX5 & disease causing / 1 & ho: $n=3$; het: $n=3$ \\
\hline c.1653delG* & E11 & p.Lys553ArgfsX75 & disease causing / 1 & ho: $n=0$; het: $n=1$ \\
\hline
\end{tabular}

CDS: coding DNA sequence; E: exon; ho: homozygous individuals: het: heterozygous individuals.

Table 2C. Splice site mutations in congenital amegakaryocytic thrombocytopenia patients.

\begin{tabular}{|c|c|c|c|c|c|c|c|}
\hline CDS & Intron & HSF prediction & $\begin{array}{c}\text { MaxEnt } \\
\text { (ut/mut) }\end{array}$ & $\begin{array}{c}\text { MDD } \\
\text { (wt/mut) }\end{array}$ & $\begin{array}{c}\text { MM } \\
\text { (wt/mut) }\end{array}$ & $\begin{array}{c}\text { WMM } \\
\text { (wt/mut) }\end{array}$ & incidence \\
\hline c. $79+2 \mathrm{~T}>\mathrm{A}$ & Il & most prob. broken donor s. & $9.16 / 0.97$ & $13.98 / 5.79$ & $9.62 / 1.43$ & $10.39 / 2.21$ & ho: $n=1$; het: $n=1$ \\
\hline c. $212+1 \mathrm{G}>\mathrm{A}$ & I2 & most prob. broken donor s. & $9.00 / 0.82$ & $11.78 / 3.60$ & $9.27 / 1.08$ & $7.15 /-1.03$ & ho: $n=0$; het: $n=1$ \\
\hline c. $213-1 \mathrm{G}>\mathrm{A}$ & I2 & most prob. broken acc. s. & $7.90 /-0.85$ & - & $7.69 /-1.06$ & $6.71 /-2.04$ & ho: $n=0$; het: $n=1$ \\
\hline c. $391+5 \mathrm{G}>\mathrm{C}$ & I3 & most prob. broken donor s. & $9.14 / 6.25$ & $12.18 / 9.98$ & $8.32 / 4.76$ & $9.69 / 5.86$ & ho: $n=0$; het: $n=5$ \\
\hline c. $1469-2 \mathrm{~A}>\mathrm{T}$ & I9 & most prob. broken acc. s. & $8.25 /-0.11$ & - & $9.41 / 1.05$ & $11.03 / 2.67$ & ho: $n=0$; het: $n=1$ \\
\hline (c.1653+1delG* & I11 & new donor site 1 base $5^{\prime}$ & $10.90 / 8.40$ & $15.68 / 12.58$ & $10.63 / 7.39$ & $9.35 / 6.49$ & ho: $n=0$; het: $n=1$ ) \\
\hline
\end{tabular}

CDS: coding DNA sequence; I: Intron; ho: homozygous; het: heterozygous. HSF: Human Splicing Finder; Max/En: MaxEntScan algorithm; wt: wild-type; mut: mutant; MM: Markov model; WMM: weighted matrix method. 
Table 2D. Missense mutations in congenital amegakaryocytic thrombocytopenia patients

\begin{tabular}{|c|c|c|c|c|c|c|}
\hline CDS & Exon & protein & MutationTaster & PROVEAN & SIF & incidence \\
\hline c. $23 \mathrm{~T}>\mathrm{G}$ & E1 & p.Met8Arg & polymorphism / 0.963 & polymorphism / 0.963 & damag. /0.004 & ho: $n=1$; het: $n=0$ \\
\hline c. $304 \mathrm{C}>\mathrm{T}$ & E3 & p.Arg102Cys & disease causing / 1.000 & disease causing / 1.000 & toler. / 0.064 & ho: $n=1$; het: $n=1$ \\
\hline c. $305 \mathrm{G}>\mathrm{A}$ & E3 & p.Arg102His & disease causing $/ 0.983$ & disease causing $/ 0.983$ & toler. / 0.291 & ho: $n=0$; het: $n=1$ \\
\hline c. $305 \mathrm{G}>\mathrm{C}$ & E3 & p.Arg102Pro & disease causing / 0.995 & disease causing / 0.995 & toler. / 0.082 & ho: $n=4$; het: $n=5$ \\
\hline c. $.311 \mathrm{~T}>\mathrm{C}$ & E3 & p.Phe104Ser & disease causing / 0.975 & disease causing / 0.975 & damag. / 0.001 & ho: $n=0$; het: $n=1$ \\
\hline c. $404 \mathrm{C}>\mathrm{G}$ & $\mathrm{E} 4$ & p.Prol35Arg & disease causing / 0.995 & disease causing / 0.995 & damag. / 0.000 & ho: $n=0$; het: $n=1$ \\
\hline c. $407 \mathrm{C}>\mathrm{A}$ & $\mathrm{E} 4$ & p.Prol36His & disease causing / 0.991 & disease causing / 0.991 & damag. / 0.000 & ho: $n=1$; het: $n=0$ \\
\hline c. $407 \mathrm{C}>\mathrm{T}$ & E4 & p.Prol36Leu & disease causing / 1.000 & disease causing / 1.000 & damag. / 0.000 & ho: $n=0$; het: $n=2$ \\
\hline c. $407 \mathrm{C}>\mathrm{G}$ & $\mathrm{E} 4$ & p.Prol36Arg & disease causing / 0.995 & disease causing / 0.995 & damag. / 0.000 & ho: $n=0$; het: $n=1$ \\
\hline c. $460 \mathrm{~T}>\mathrm{C}$ & E4 & p.Trp154Arg & disease causing / 0.984 & disease causing / 0.984 & damag. / 0.000 & ho: $n=2$; het: $n=0$ \\
\hline c. $506 \mathrm{~T}>\mathrm{A}$ & E4 & p.Leul69His & disease causing / 0.903 & disease causing / 0.903 & damag. / 0.001 & ho: $n=1$; het: $n=1$ \\
\hline c. $769 \mathrm{C}>\mathrm{T}$ & E5 & p.Arg257Cys & disease causing / 1.000 & disease causing / 1.000 & damag. / 0.002 & ho: $n=0$; het: $n=2$ \\
\hline c. $770 \mathrm{G}>\mathrm{T}$ & E5 & p.Arg257Leu & disease causing /1.000 & disease causing $/ 1.000$ & damag. / 0.005 & ho: $n=1$; het: $n=0$ \\
\hline c. $805 \mathrm{~T}>\mathrm{C}$ & E5 & p.Trp269Arg & disease causing / 0.994 & disease causing / 0.994 & damag. / 0.000 & ho: $n=1$; het: $n=0$ \\
\hline c. $823 \mathrm{C}>\mathrm{A}$ & E5 & p.Pro275Thr & disease causing / 0.985 & disease causing / 0.985 & damag. / 0.008 & ho: $n=0$; het: $n=1$ \\
\hline c. $.883 \mathrm{G}>\mathrm{C}$ & E6 & p.Asp295Tyr & disease causing / 0.998 & disease causing / 0.998 & damag. / 0.002 & ho: $n=2$; het: $n=0$ \\
\hline c. $944 \mathrm{~T}>\mathrm{G}$ & $\mathrm{E} 6$ & p.Phe315Cys & disease causing / 0.999 & disease causing / 0.999 & damag. / 0.003 & ho: $n=0$; het: $n=1$ \\
\hline c. $1180 \mathrm{C}>\mathrm{T}$ & E8 & p.Pro394Ser & disease causing / 0.981 & disease causing / 0.981 & damag. / 0.004 & ho: $n=2$; het: $n=0$ \\
\hline c. $1305 \mathrm{G}>\mathrm{C}$ & E8 & p.Trp435Cys & disease causing / 1.000 & disease causing / 1.000 & damag. / 0.000 & ho: $n=2$; het: $n=0$ \\
\hline c. $1361 \mathrm{G}>\mathrm{C}$ & E9 & p.Arg454Pro & polymorphism / 1.000 & polymorphism / 1.000 & toler. / 0.391 & ho: $n=1$; het: $n=0$ \\
\hline c. $1390 \mathrm{~A}>\mathrm{G}$ & E9 & p.Arg464Gly & polymorphism / 0.993 & polymorphism / 0.993 & damag. / 0.006 & ho: $n=1$; het: $n=0$ \\
\hline c. $1571 \mathrm{~T}>\mathrm{G}$ & E11 & p.Leu524Arg & disease causing / 0.807 & disease causing / 0.807 & damag. / 0.002 & ho: $n=1$; het: $n=0$ \\
\hline c. $1742 \mathrm{C}>\mathrm{T}$ & E12 & p.Pro581Leu & disease causing / 0.981 & disease causing / 0.981 & damag. / 0.004 & ho: $n=1$; het: $n=0$ \\
\hline c. $1781 \mathrm{~T}>\mathrm{G}$ & $\mathrm{E} 12$ & p.Leu594Trp & polymorphism / 0.986 & polymorphism / 0.986 & damag. / 0.000 & ho: $n=0$; het: $n=1$ \\
\hline
\end{tabular}

CDS: coding DNA sequence; ho: homozygous individuals: het: heterozygous individuals.

THPO values, despite complete MPL deficiency, could be due to recent platelet transfusions or duration and condition of sample shipment.

\section{Clinical phenotype \\ Inheritance}

Twenty-nine $(52 \%)$ of the patients in our cohort had consanguineous parents and were homozygous for the particular MPL mutation. Homozygous mutations in patients with no evidence for parental consanguinity $(n=9)$ were mainly affected from the most prevalent mutation c.305G $>C$ ( $n=4)$ or from mutations with a higher prevalence in a specific region (c.506T $>\mathrm{A}$, see above) or ethnic group (c.79+2T>A). ${ }^{28}$

Some families had more than one affected patient: CAMT009 + CAMT031, CAMT018 + CAMT019 + CAMT036 + CAMT180, and CAMT133 + CAMT140 each belongs to large kindreds with a high degree of consanguinity. Other cases of CAMT, aplastic anemia or not otherwise specified "bleeding disease" are reported in these kindreds. CAMT101 and CAMT102 as well as CAMT130 and CAMT137 are siblings from non-consanguineous families. CAMT083 is the fetus of a second pregnancy of the mother of CAMT052. Bone marrow analysis during autopsy revealed normal cellularity with absent megakaryocytes.

\section{Pregnancies, deliveries, symptoms at birth}

Pregnancies and deliveries were unremarkable in the majority of the cases. Median gestational age was 40 weeks ( $n=34$, range, 31-42 weeks of gestation [wGA]), mean birth weight $3,080 \mathrm{~g}(\mathrm{n}=25$, range, 1,545-4,280 g).

Intracranial bleeding in utero was detected in some patients (seven of 46), ${ }^{\dagger}$ retrospectively in four of seven. Two children were delivered by cesarean section due to diagnosis of cerebral hemorrhage: CAMT013 with a hydrops fetalis due to Rhesus incompatibility (wGA 31) and CAMT123 after an intracranial bleeding in wGA 28 (wGA 38). Pregnancy of CAMT083 was terminated in wGA 22 because of very poor prognosis after intracranial bleeding. There were three other cesarean sections for reasons only related to the mother.

We found a significant female predominance in our cohort $\left(62.5 \%, P<0.05\right.$ according to $\chi^{2}$-test). ${ }^{2}$ This is in contrast to most of the other IBMFS in which boys are affected more often. ${ }^{29}$ We have no information about the number and sex ratio of miscarriages in the patients' families as a possible hint for the female predominance.

\section{Thrombocytopenia, bleeding}

Although thrombocytopenia at birth has been classified as one of the diagnostic hallmarks of CAMT so far, 13 of $52^{\dagger}$ patients in this study with available information showed no signs of thrombocytopenia at birth and no blood counts were taken. Twelve of 13 patients had mutations allowing for a residual MPL activity. In the remaining patients (39 of 52$)^{\dagger}$ thrombocytopenia was detected at birth $(n=38)$ or at termination of pregnancy $(n=1)$. Available data for platelet counts at birth ranged from 1-36 G/L (median $15 \mathrm{G} / \mathrm{L}, \mathrm{n}=30$ ). Petechiae or pur- 


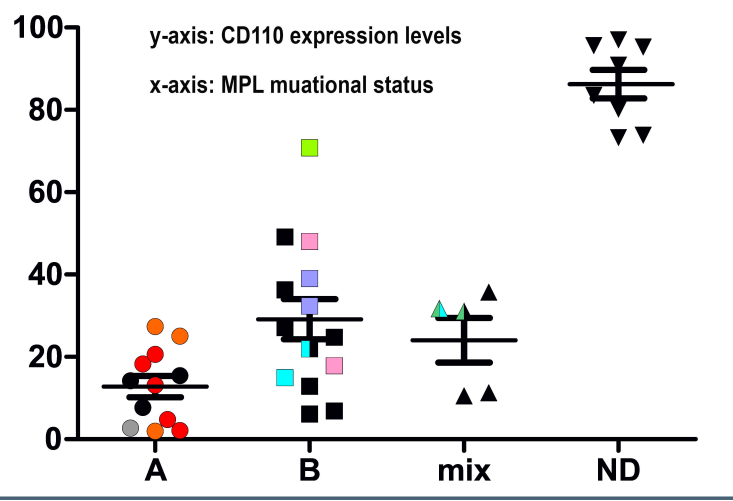

Figure 2. MPL expression on CD34+CD38lo hematopoietic progenitors from congenital amegakaryocytic thrombocytopenia patients The figure shows CD110 expression levels, calculated from cumulative subtraction on CD34+CD38lo hematopoietic progenitors of patients with nonsense, frame shift mutations or splice site mutations predicted to lead to a complete loss of MPL function (A), missense mutations (B), or patients who are compound heterozygous for different types of mutations (mix), in comparison to normal donors (ND). Horizontal lines represent the mean and standard error of the mean. Data from samples with special genotypes are labeled with the same colors, respectively. A+B: red: p.Arg43Ter, orange: p.Phe126LeufsTer5, grey: c.79+2T>A; green: p.Arg454Pro, pink: p.Leu169His, violet: p.Asp295Tyr, blue: p.Arg102Pro (half: compound heterozygous with p.Phe104Ser); mix: dark green/blue: c.391+5G>C/p.Arg102Pro, dark green/black: c.391+5>C/p.Arg257Cys.

pura at birth or in the first week of life were the presenting symptoms of thrombocytopenia in the majority of cases $(25 \text { of } 38)^{\dagger}$. Only few patients (five of 38$)^{\dagger}$ presented with severe bleedings at birth $(n=3)$ or shortly thereafter $(n=2)$. Intracranial bleedings was reported only during pregnancy $(n=7)$, at birth $(n=2)$ or within the first 4 weeks of life $(n=4)$. Hematemesis as an indication of gastrointestinal bleeding was observed in one patient (at birth). In contrast to intracranial and gastrointestinal bleeding, severe episodes of epistaxis were reported mainly during the later stages of the disease $(n=3)$.

Data regarding platelet courses confirmed our concept of CAMT I and CAMT II distinguishing between patients with severely low platelet counts over the whole course of the disease due to loss-of-function mutations in MPL (CAMT I) and those patients showing a spontaneous increase of platelet counts in the first months of life due to a residual function of the receptor (CAMT II): ${ }^{4,14,15}$ platelet counts over $50 \mathrm{G} / \mathrm{L}$ (not transfused) within the first year of life have been documented for 14 of $33^{\dagger}$ patients. For nine more patients with a late diagnosis of thrombocytopenia we can also assume higher platelet counts in the first months of life. None of these 23 patients bore a mutation predicted to lead to a complete loss of function. Nearly all CAMT I and CAMT II patients demonstrated a further decline of platelet counts during the development of aplastic anemia. Platelet counts of heterozygously affected parents and siblings of patients were in a normal range with the exception of one parent (c.305G $>$ C) with mild thrombocytopenia (130-150 G/L).

\section{Development of pancytopenia}

Development of additional anemia or neutropenia and reduced bone marrow cellularity are signs of developing bone marrow exhaustion. Bone marrow analyses from the first 6 months of life usually showed normal cellularity with reduced or absent megakaryocytes (13 of 15$).^{\dagger}$ Accordingly, most of the patients presented with isolated
Table 3. Non-hematological findings in congenital amegakaryocytic thrombocytopenia patients.

\begin{tabular}{|c|c|c|}
\hline & \# of patients (with ICH) & HPO-designation \\
\hline Data available & 50 & \\
\hline No non-hematological findings & 25 & \\
\hline $\begin{array}{l}\text { Abnormality of fetal development } \\
\text { hydrops fetalis }\end{array}$ & $\begin{array}{l}1(1) \\
1(1)\end{array}$ & $\begin{array}{r}\text { HP:0001197 } \\
\text { HP:0001789 }\end{array}$ \\
\hline $\begin{array}{l}\text { Anomalies of the nervous system } \\
\text { optic nerve hypoplasia } \\
\text { cerebellar hypoplasia } \\
\text { agenesis of corpus callosum } \\
\text { Dandy-Walker anomaly } \\
\text { arachnoid cyst } \\
\text { ventriculomegaly } \\
\text { colpocephaly } \\
\text { hydrocephalus }\end{array}$ & $\begin{array}{l}7(6) \\
1(1) \\
1(1) \\
1(1) \\
2(2) \\
3(2) \\
1(1) \\
1(1) \\
1(1)\end{array}$ & $\begin{array}{r}\text { HP:0000707 } \\
\text { HP:0000609 } \\
\text { HP:0001321 } \\
\text { HP:0001274 } \\
\text { HP:0001305 } \\
\text { HP:0100702 } \\
\text { HP:0002119 } \\
\text { HP:0030048 } \\
\text { HP:0000238 }\end{array}$ \\
\hline Mental/psychomotor retardation & $7(5)$ & HP:0001263 \\
\hline $\begin{array}{l}\text { Abnormality of the skin } \\
\text { eczema } \\
\text { hypopigmentation } \\
\text { atopic dermatitis }\end{array}$ & $\begin{array}{l}4 \\
2(0) \\
1(0) \\
1(0)\end{array}$ & $\begin{array}{r}\text { HP:0000951 } \\
\text { HP:0000964 } \\
\text { HP:0001010 } \\
\text { HP:0001047 }\end{array}$ \\
\hline $\begin{array}{l}\text { Abnormalities of the eye } \\
\text { impaired vision } \\
\text { nystagmus } \\
\text { strabismus }\end{array}$ & $\begin{array}{l}10 \\
1(1) \\
4(3) \\
9(5)\end{array}$ & $\begin{array}{r}\text { HP:0000478 } \\
\text { HP:0000505 } \\
\text { HP:0000639 } \\
\text { HP:0000486 }\end{array}$ \\
\hline $\begin{array}{l}\text { Abnormalities of the face } \\
\text { hypertelorism } \\
\text { high palate } \\
\text { small uvula }\end{array}$ & $\begin{array}{l}4(1) \\
2(1) \\
2(0) \\
1(0)\end{array}$ & $\begin{array}{r}\text { HP:0000271 } \\
\text { HP:0000316 } \\
\text { HP:0000218 } \\
\text { HP:0010812 }\end{array}$ \\
\hline Skeletal abnormalities & 0 & HP:0000924 \\
\hline Cardiovascular abnormalities & 0 & HP:0001626 \\
\hline $\begin{array}{l}\text { Abnormalities of the } \\
\text { genitourinary system }\end{array}$ & 0 & HP:0000119 \\
\hline $\begin{array}{l}\text { Other abnormalities } \\
\text { obstructive sleep apnea } \\
\text { diabetes } \\
\text { short stature }\end{array}$ & $\begin{array}{l}2(0) \\
1(0) \\
1(0) \\
1(0)\end{array}$ & $\begin{array}{l}\text { HP:0002870 } \\
\text { HP:0000819 } \\
\text { HP:0004322 } \\
\end{array}$ \\
\hline
\end{tabular}

Non-hematologic abnormalities found in congenital amegakaryocytic thrombocytopenia (CAMT) patients with homozygous or compound heterozygous mutations in MPL with the respective designations according to the human phenotype ontology (HPO) ${ }^{57}$ Number of patients with documented intracranial hemorrhages $(\mathrm{ICH})$ in parentheses.

thrombocytopenia at birth or in the first weeks thereafter (36 of 51). ${ }^{\dagger}$ Only six patients showed signs of multi-lineage cytopenia within the first 6 months of live, four of them were already anemic immediately after birth (hemoglobin 56-76 g/L). For two patients a hypocellular bone marrow is documented in the first month after birth.

Provided the data available at time of analysis only seven of 49 patients showed no signs of developing pancytopenia. Five of these patients were younger than 2 years at last examination.

From the remaining 42 patients with documented aplasia only $24 \%$ were older than 4 years $(n=10)$. Seventy-six percent $(n=32)$ were younger than 4 years, half of them even younger than 2 years (Online Supplementary Figure S1). CAMT011 is the only patient without any signs of pancytopenia till adulthood.

t Here and in all subsequent ratios, the denominator is the number of patients for whom information is available for a specific parameter. E.g., for "intracranial bleeding" 46 is the number of questionnaires with a yes-no-information from the attending physicians. 
Table 4. Hematopoietic stem cell transplantation in congenital amegakaryocytic thrombocytopenia.

\begin{tabular}{|c|c|c|c|c|c|c|}
\hline & $\begin{array}{l}\text { \# of pts with } \\
\text { available info }\end{array}$ & & N & $\%$ & os outcome (\%) & $\begin{array}{l}\text { information about neg. } \\
\text { outcome }\end{array}$ \\
\hline \multirow[t]{3}{*}{ Age at $1^{\text {st }}$ HSCT [y] } & \multirow[t]{3}{*}{38} & $\begin{array}{l}\text { Median: } 3.55 \text { y, range: } 0.6-11 \text { y } \\
<1 \text { year } \\
1-5 \text { years }\end{array}$ & $\begin{array}{c}5 \\
23\end{array}$ & $\begin{array}{l}13 \\
61\end{array}$ & $\begin{array}{l}4 / 4(100) \\
15 / 17(88)\end{array}$ & $\begin{array}{l}\text { CAMT039: TRD (no details, } \\
\text { BM, MUD) } \\
\text { CAMT015: death after } \\
\text { GvHD-induced bronchiolitis } \\
\text { obliterans (BM, MUD) }\end{array}$ \\
\hline & & \multirow[t]{2}{*}{$>5$ years } & \multirow[t]{2}{*}{10} & \multirow[t]{2}{*}{26} & \multirow[t]{2}{*}{ 7/9 (78) } & $\begin{array}{l}\text { CAMT007: death after graft } \\
\text { rejection and sepsis } \\
\text { (PBSC, MUD) }\end{array}$ \\
\hline & & & & & & $\begin{array}{l}\text { CAMT157: death after GvHD } \\
\text { grade } 4 \text { (lung, skin) and sepsis } \\
\text { (CB) }\end{array}$ \\
\hline
\end{tabular}

\begin{tabular}{|c|c|c|c|c|c|}
\hline HSC donor & 34 & $\begin{array}{l}\text { HLA matched related donor } \\
\text { haploident related donor } \\
\text { matched unrelated donor } \\
\text { mismatched unrelated donor }\end{array}$ & $\begin{array}{c}19 \\
3 \\
11 \\
1\end{array}$ & $\begin{array}{c}56 \\
9 \\
32 \\
3\end{array}$ & $\begin{array}{c}12 / 12(100) \\
4 / 4(100) \\
5 / 8(63) \\
1 * / 1(100)\end{array}$ \\
\hline HSC source & 22 & $\begin{array}{l}\text { BM } \\
\text { PBSC } \\
\text { CB }\end{array}$ & $\begin{array}{l}10 \\
7 \\
5\end{array}$ & $\begin{array}{l}48 \\
33 \\
19\end{array}$ & $\begin{array}{c}8 / 10(80) \\
6 / 7(86) \\
3 / 4(75)\end{array}$ \\
\hline
\end{tabular}

The table summarizes the available information regarding age of hematopoietic stem cell transplantation (HSCT), donor and source of hematopoietic stem cell (HSC) and outcome. Information about outcome was not available for all transplantations. BM: bone marrow; CB: cord blood, PBSC: peripheral blood stem cells; pts: patients; TRD: transplantation related death; ${ }^{*}$ : CB, 1 mismatch. GvHD: graft-versus-host disease; MUD: matched unrelated donor.

\section{Chromosomal anomalies, leukemic development}

Cytogenetic data were inconspicuous for most of the patients with available data $(n=23$ of $27,85 \%)$. An abnormal karyotype has been detected in 4 patients: t2;11 (5\%) in CAMT009, ${ }^{14}$ a not further specified additional marker chromosome $(94 \%)$ in CAMT013 ${ }^{14}$ and monosomy 7 in CAMT043 $^{30}(50 \%)$ and CAMT067 (13-30\%). The latter has been diagnosed with MDS. All underwent hematopoietic stem cell transplantation (HSCT) because of aplastic anemia. In none of the patients a development of overt leukemia has been reported in the period of record.

\section{Non-hematological abnormalities}

The rate of non-hematological abnormalities in our CAMT-MPL patients was markedly higher than reported: $50 \%$ of the patients with available data (25 of 50) had non-hematological abnormalities appearing as structural abnormalities or other abnormal clinical findings (Table 3). Most of the reported anomalies were related to the head region: brain anomalies $(n=7)$, ocular and orbital anomalies $(n=10)$, especially strabismus $(n=$ 9), nystagmus $(n=4)$ and facial abnormalities $(n=4)$. Mental or psychomotor retardation was observed in seven patients, mostly correlated with brain anomalies. Intracranial bleedings are documented for five of seven patients with mental or psychomotor retardation, for six of seven with brain anomalies, and for six of ten with ocular anomalies (Table 3). Interestingly, we found some anomalies which are typical for other IBMFS and which misled the first diagnosis: eczema $(n=2)$, hypopigmentation $(n=1)$, high palate and/or small uvula $(n=2)$. No skeletal, cardiac or urogenital abnormalities were observed. There was no correlation between type or localization of MPL mutations and non-hematological abnormalities.

\section{Treatment}

Thirty-seven of 45 documented cases of our patient group received platelet transfusions, most of them transiently in a period immediately after diagnosis of severe thrombocytopenia and/or during the aplastic stage of the disease. During the advanced stage of the pancytopenia the patients often received erythrocyte transfusions (16 of 45). Neutropenia and associated infections were treated with antibiotics; two of the patients were treated with recombinant granulocyte colony-stimulating factor.

Half of the patients ( 25 of 50 ) have been initially treated with immunoglobulins (23 of 50) or corticosteroids (15 of 50). Interestingly, three patients responded with a transient increase in platelet counts, which initially misled the diagnosis but none showed a persistent response.

The only available curative treatment for CAMT-MPL is HSCT. Thirty-eight of 51 patients in our group were treated with HSCT, for another ten HSCT was planned for the near future. For 26 of 30 patients with information about the post-transplant course a positive outcome was documented ( $87 \%)$. The available information about age of transplantation, donor, stem cell source and outcome is summarized in Table 4.

Three patients were unsuccessfully treated with recombinant IL-11 (oprelvekin). Two of them showed a slight and transient increase in platelet counts, followed by a prolonged phase of severe thrombocytopenia, which could be explained by an exhaustion of residual megakaryopoiesis by stimulation of cytoplasmic maturation.

\section{Congenital amegakaryocytic thrombocytopenia with only one affected MPL allele}

In six patients with clinical diagnosis of CAMT we found only a single mutated allele (Online Supplementary Table S3), as judged by reproducible balanced distribution 
of both alleles from independently isolated genomic DNAs in five patients and an unbalanced distribution of both alleles in one patient.Two of these six patients were from families with other members affected by CAMTMPL: CAMT139 was heterozygously affected by the missense mutation c.1390A>G, homozygously detected in her sister CAMT138. Both sisters had similar clinical and laboratory findings. Both parents were heterozygous carrier of the mutation without any hematological problems. Thrombopoietin plasma levels were high in both sisters but not in the parents. However, in contrast to both parents who demonstrated a balanced distribution of both alleles the wild-type allele in CAMT139 was reproducibly markedly underrepresented (approximatly $20 \%$ ), arguing for somatic mosaicism. Patient CAMT065 heterozygously harbored the c.127C $>$ T nonsense mutation, which was homozygously found in his cousins CAMT036 and CAMT018. Besides these familial cases we identified four other patients with heterozygous MPL mutations. In one of these patients (CAMT129) we found CD110 expression on early hematopoietic progenitors comparable to that from patients with a predicted complete loss of the receptor (Figure 2). In patient CAMT73 we found a novel nonsense mutation in exon 7 together with a synonymous substitution c.585T>C (p.Pro195=). Although synonymous mutations can significantly influence protein levels via changes in translation efficiency, ${ }^{31}$ both codons are nearly equally used in human genes, and the mutation has no predicted effect on splicing.

\section{Discussion}

This report summarizes the results of a long term study on the largest cohort of patients with CAMT-MPL caused by biallelic mutations in MPL. We limited our cohort to this group of patients (i) to provide a reliable definition of the clinical picture of CAMT-MPL, (ii) to define the effects of the MPL/THPO system in humans, and (ii) to allow for evidence based treatment recommendations.

CAMT has been used in the past to describe an IBMFS with no characteristic malformations presenting as isolated thrombocytopenia at birth progressing to a general bone marrow failure. ${ }^{13,32}$ However, large differences in the reported percentages for $M P L$ mutations, for the development of aplastic anemia and leukemia, and for somatic malformations reveal differences in the definition of this disease. ${ }^{29,3335}$ This together with misleading combinations of findings from the pre-molecular era involves the risk of mistreatment e.g., HSCT of patients with CAMT due to THPO mutations.

The most severe clinical problems for patients with CAMT-MPL are (i) - so far underestimated - pre- and perinatal bleedings and the resulting long-term consequences thereof, and (ii) the development of aplastic anemia in the later course of the disease.

Severe bleedings, especially intracranial bleedings, occur mainly pre- or perinatally but much less frequently after the first weeks of life despite partly very low platelet counts. Specific functional deficits in neonatal platelets like a decreased P-Selectin expression and reduced platelet activation and secretion ${ }^{36.38}$ could be a possible explanation for the high bleeding tendency pre- or perinatally in combination with the thrombocytopenia. Furthermore, both life-span and thrombin dependent activation of platelet GPIIb/IIIa are markedly reduced in neonatal $\mathrm{Mpt}^{-/ 2}$ mice compared to adult $\mathrm{Mpt}^{1-}$ mice..$^{37}$ Our results indicate a possible functional impairment of platelets also in human fetuses and newborns with MPL defect which is in contrast to the assumption of a normal function of $\mathrm{Mpt}^{\text {t/ }}$ platelets. ${ }^{39}$

Development of aplastic anemia due to exhaustion of three lineage hematopoiesis is a characteristic feature of CAMT-MPL and reveals the essential role of MPL for the maintenance of hematopoietic stem cells: $:^{40}$ almost all patients inevitably develop a fatal bone marrow failure. In our study we observed only one patient with an isolated thrombocytopenia until adulthood. In the literature one further patient is described with stable thrombocytopenia in the period of record. ${ }^{41}$

Half of the patients in our cohort exhibit non-hematopoietic abnormalities. This is in contrast to the characterization of CAMT as an IBMF with no physical anomalies (OMIM). Most of the non-hematopoietic abnormalities seen in our cohort are related to the brain and the eye. For neurological abnormalities, which have been reported for other CAMTMPL patients it has been argued, that these could be a direct consequence of the roles of thrombopoietin and MPL in the brain. ${ }^{42-45}$ However, the high correlation between structural abnormalities in the brain and intracranial bleedings argues for a secondary effect of thrombocytopenia. Indeed, most of these structural abnormalities observed in our cohort have also been reported as a consequence of intracranial bleedings, ${ }^{46-48}$ even strabismus and nystagmus. ${ }^{49}$ This is further supported by the observation that higher incidences of ocular anomalies have also been described for other BMFS going along with thrombocytopenia (Fanconi anemia, dendritic cells) but not for those with normal platelet counts (Diamond Blackfan anemia, Shwachman Diamond syndrome). ${ }^{50}$ Previous reports of other non-hematological abnormalities refer to CAMT patients with unreported or wild-type MPL genotype. ${ }^{14,51}$ Our data suggests that the primary effects of MPL deficiency are restricted to the hematopoietic system - most of the non-hematopoietic symptoms seem to be secondary to the thrombocytopenia or bone marrow failure. For other symptoms, especially those observed only in single cases or in highly consanguineous families ${ }^{52}$ we suppose that they emerged coincidentally.

Although CAMT is regarded to be a preleukemic syndrome in most of the recent reviews, only weak evidence for this assumption exists. One single patient with CAMT and confirmed MPL mutation has been reported to develop a pre-B acute lymphoblastic leukemia. ${ }^{41}$ Increased accumulation of chromosomal aberrations, however, has been observed in our and previous studies. ${ }^{53}$ The exhaustion of hematopoietic stem cells due to MPL deficiency may be the reason for both, the acquisition of pre-leukemic cellular alterations due to increased hematopoietic stress, but also for early development of aplastic anemia leading to death or replacement of the hematopoietic system by means of HSCT, thereby preventing the development of overt leukemia. The debate about CAMT-MPL as a preleukemic syndrome therefore might be of less relevance.

Genotype-phenotype correlations in CAMT-MPL have led us to our concept of CAMT I and II groups: a complete loss of MPL function results in persistently low platelet counts and a fast progression into pancytopenia in CAMT I patients whereas a residual function of the receptor leads to a milder course with a transient increase of platelet counts 
in the first year of life in CAMT II patients., ${ }^{414,15}$

The data from the present study allow for additional conclusions of clinical relevance:

- the course of the disease is mainly determined by the type of mutation. The same MPL mutations lead to high similarities in the hematological courses of patients, even if they are from different families or different ethnical background (e.g., mild course in patients with c.391+5G>C).

- the time course of pancytopenia development for patients with same MPL mutations is more variable than the course of thrombocytopenia. This could be caused by accelerated exhaustion of hematopoietic progenitors due to frequent bleedings or infections in some patients. ${ }^{54}$

- all patients with mutations leading to a complete loss of function (CAMT I) had a similar course with constantly severe thrombocytopenia. Platelet counts at birth and in the further course never exceed 50 . and all of them showed a transition to pancytopenia. A complete MPL deficiency is probable in patients showing signs of aplastic anemia in the first months of life.

- missense mutations predicted to allow a residual function of the MPL receptor lead to a more variable course of CAMT. The most severe phenotypes, comparable to CAMT I (severe thrombocytopenia, early development of aplasia), were observed in patients with mutations p.Leu169His and p.Trp154Arg. Milder phenotypes (late detection of thrombocytopenia and delayed development of aplasia) were observed in patients with mutations p.Asp295Tyr and p.Pro394Ser and missense mutations affecting the intracytoplasmic domain.

- milder phenotypes with late development of aplastic anemia (respectively none during the period of record) have also been observed in patients with splice site mutations allowing for a residual normal splicing, ${ }^{26,41}$ namely c. $391+5 \mathrm{G}>\mathrm{C}$ and c. $212+5 \mathrm{G}>\mathrm{A}$.

- patients with germ line MPL mutations and a late onset form of amegakaryocytic thrombocytopenia or aplastic anemia (e.g., patients CAMT058, CAMT101, CAMT102 with moderate thrombocytopenia detected at the age of $>2$ years) should be also regarded as CAMT-MPL. This includes the patients previously described as familial aplastic anemia..$^{5}$

- there may exist a small subgroup of CAMT II patients without development of pancytopenia. For patients with new mutations predicted to have minor impact on function or with mutations previously detected in patients with a mild course (namely c.391+5G>C, c.212+5G $>$ A, or p.Pro275Thr) it might be appropriate to wait for first signs of bone marrow failure before proceeding to HSCT, especially if no appropriate family donor is available.

- type and localization of MPL mutations are not predictive for pre- and perinatal intracranial hemorrhages. There are no differences in the frequency and severity of these bleedings between patient groups CAMT I and CAMT II. The existence of a deleterious MPL mutation is a major risk factor for the occurrence of intracranial bleedings.

- structural and clinical non hematologic abnormalities in CAMT-MPL are not correlated with specific mutations.

- there is a small group of patients who present clinically as CAMT, but in whom a deleterious MPL mutation can only be detected in one allele. Possible explanations for the seeming inconsistency between genotype and phenotype include somatic mosaicism, deletions or changes in regulatory sequences that prevent the translation of a functional protein, or - rather unlikely especially in family cases - accidental coincidence.

- a further consideration for clinical presentation of CAMT-MPL is whether, in addition to existing MPL mutations, mutations or functional single nucleotide polymorphisms in other genes or epigenetic differences are involved in the observed phenotypic heterogeneity of CAMT-MPL

Our analysis of a large cohort of CAMT-MPL patients demonstrates a higher variability of clinical courses than described so far. The diagnosis CAMT-MPL has to be considered even for those patients who are inconspicuous in the first months of life or show somatic anomalies typical for other BMFS. Since almost all CAMT-MPL patients inevitably develop a fatal bone marrow failure that requires treatment with HSCT, all children with unclear forms of hypomegakaryocytic thrombocytopenia should be tested for MPL mutations. If molecular confirmation of CAMT is not possible, at least those IBMFS should be excluded for which HSCT is not an option (e.g., thrombopoietin production defect) or which need another transplantation regimen (e.g., Fanconi anemia, Diamond Blackfan anemia).

\section{Disclosures}

No conflicts of interest to disclose

\section{Contributions}

$M G$ and $M B$ designed and performed research, analyzed data, and wrote the manuscript.

\section{Acknowledgments}

The authors would like to thank all patients and their families who participated in this study. We are also grateful to the physicians who provided us with material and data from their patients. We would like to acknowledge the excellent technical assistance of Yvonne Peter and Christina Struckmann.

\section{Funding}

This work was supported in part by grants from the Federal Ministry of Education and Research (German Network on Congenital Bone Marrow Failure Syndromes) and by the transnational ERA-NET funding European Platelet Network (EUPLANE).

\section{References}

1. Ballmaier M, Germeshausen M. Advances in the understanding of congenital amegakaryocytic thrombocytopenia. Br J Haematol. 2009;146(1):3-16.

2. Ballmaier M, Germeshausen M. Congenital amegakaryocytic thrombocytopenia: clinical presentation, diagnosis, and treatment. Semin Thromb Hemost. 2011;37(6):673-681.

3. Ihara K, Ishii E, Eguchi M, et al. Identification of mutations in the c-mpl gene in congenital amegakaryocytic thrombocytopenia. Proc
Natl Acad Sci U S A. 1999;96(6):3132-3136.

4. Ballmaier M, Germeshausen M, Schulze H, et al. c-mpl mutations are the cause of congenital amegakaryocytic thrombocytopenia. Blood. 2001;97(1):139-146.

5. Dokal I, Vulliamy T. Inherited bone marrow failure syndromes. Haematologica. 2010;95 (8):1236-1240.

6. Dasouki MJ, Rafi SK, Olm-Shipman AJ, et al. Exome sequencing reveals a thrombopoietin ligand mutation in a Micronesian family with autosomal recessive aplastic anemia. Blood. 2013;122(20):3440-3449.
7. Seo A, Ben-Harosh M, Sirin M, et al. Bone marrow failure unresponsive to bone marrow transplant is caused by mutations in thrombopoietin. Blood. 2017;130(7):875-880.

8. Pecci A, Ragab I, Bozzi V, et al. Thrombopoietin mutation in congenital amegakaryocytic thrombocytopenia treatable with romiplostim. EMBO Mol Med. 2018;10(1):63-75.

9. Basel-Vanagaite L, Dokal I, Tamary H, et al. Expanding the clinical phenotype of autosomal dominant dyskeratosis congenita caused by TERT mutations. Haematologica. 2008; 
93(6):943-944.

10. Giampietro PF, Verlander PC, Davis JG, Auerbach AD. Diagnosis of Fanconi anemia in patients without congenital malformations: an international Fanconi Anemia Registry Study. Am J Med Genet. 1997; 68(1):58-61.

11. Germeshausen M, Ancliff P, Estrada J, et al. MECOM-associated syndrome: a heterogeneous inherited bone marrow failure syndrome with amegakaryocytic thrombocytopenia. Blood Adv. 2018;2(6):586-596.

12. Christensen RD, Wiedmeier SE, Yaish HM. A neonate with congenital amegakaryocytic thrombocytopenia associated with a chromosomal microdeletion at $21 \mathrm{q} 22.11$ including the gene RUNX1. J Perinatol. 2013;33 (3): $242-244$.

13. Geddis AE. Congenital amegakaryocytic thrombocytopenia. Pediatr Blood Cancer. 2011;57(2):199-203.

14. King S, Germeshausen M, Strauss G, Welte $\mathrm{K}$, Ballmaier M. Congenital amegakaryocytic thrombocytopenia: a retrospective clinical analysis of 20 patients. $\mathrm{Br} \mathrm{J}$ Haematol. 2005;131(5):636-644

15. Germeshausen M, Ballmaier M, Welte K. MPL mutations in 23 patients suffering from congenital amegakaryocytic thrombocytopenia: the type of mutation predicts the course of the disease. Hum Mutat. 2006;27(3):296

16. Stoddart MT, Connor P, Germeshausen M, Ballmaier M, Steward CG. Congenital amegakaryocytic thrombocytopenia (CAMT) presenting as severe pancytopenia in the first month of life. Pediatr Blood Cancer. 2013;60(9):E94-96.

17. Ok Bozkaya I, Yarali N, Isik P, Unsal Sac R, Tavil B, Tunc B. Severe clinical course in a patient with congenital amegakaryocytic thrombocytopenia due to a missense mutation of the c-MPL gene. Turk J Haematol. 2015;32(2):172-174

18. Choi Y, Chan AP. PROVEAN web server: a tool to predict the functional effect of amino acid substitutions and indels. Bioinformatics. 2015;31(16):2745-2747.

19. Kumar P, Henikoff S, Ng PC. Predicting the effects of coding non-synonymous variants on protein function using the SIFT algorithm. Nat Protoc. 2009:4(7):1073-1081.

20. Adzhubei IA, Schmidt S, Peshkin L, et al. A method and server for predicting damaging missense mutations. Nat Methods. 2010;7 (4):248-249.

21. Schwarz JM, Cooper DN, Schuelke M, Seelow D. MutationTaster2: mutation prediction for the deep-sequencing age. Nat Methods. 2014;11(4):361-362.

22. Reese MG, Eeckman FH, Kulp D, Haussler D. Improved splice site detection in Genie. J Comput Biol. 1997;4(3):311-323.

23. Yeo G, Burge CB. Maximum entropy modeling of short sequence motifs with applications to RNA splicing signals. J Comput Biol. 2004:11(2-3):377-394

24. Desmet FO, Hamroun D, Lalande M, Collod-Beroud G, Claustres M, Beroud C. Human Splicing Finder: an online bioinformatics tool to predict splicing signals. Nucleic Acids Res. 2009;37(9):e67.

25. Ballmaier M, Holter W, Germeshausen M. Flow cytometric detection of MPL (CD110) as a diagnostic tool for differentiation of congenital thrombocytopenias. Haematologica. 2015;100(9):e341-344.
26. Gandhi MJ, Pendergrass TW, Cumming CC, Ihara K, Blau CA, Drachman JG Congenital amegakaryocytic thrombocytopenia in three siblings: molecular analysis of atypical clinical presentation. Exp Hematol. 2005;33(10):1215-1221.

27. Varghese LN, Zhang JG, Young SN, et al Functional characterization of c-Mpl ectodomain mutations that underlie congenital amegakaryocytic thrombocytopenia. Growth Factors. 2014;32(1):18-26

28. Jalas C, Anderson SL, Laufer T, et al. A founder mutation in the MPL gene causes congenital amegakaryocytic thrombocytopenia (CAMT) in the Ashkenazi Jewish population. Blood Cells Mol Dis. 2011;47(1):79-83

29. Alter BP. Diagnosis, genetics, and management of inherited bone marrow failure syndromes. Hematology Am Soc Hematol Educ Program. 2007;2007:29-39.

30. Steele M, Hitzler J, Doyle JJ, et al. Reduced intensity hematopoietic stem-cell transplantation across human leukocyte antigen barriers in a patient with congenital amegakaryocytic thrombocytopenia and monosomy 7 . Pediatr Blood Cancer. 2005;45(2):212-216.

31. Tuller T, Waldman YY, Kupiec M, Ruppin E. Translation efficiency is determined by both codon bias and folding energy. Proc Natl Acad Sci U S A. 2010;107(8):3645-3650

32. Dokal I, Vulliamy T. Inherited aplastic anaemias/bone marrow failure syndromes Blood Rev. 2008;22(3):141-153.

33. Weinzierl EP, Arber DA. The differential diagnosis and bone marrow evaluation of new-onset pancytopenia. Am J Clin Pathol. 2013;139(1):9-29.

34. Rivers A, Slayton WB. Congenital cytopenias and bone marrow failure syndromes. Semin Perinatol. 2009;33(1):20-28.

35. Geddis AE. Inherited thrombocytopenia: Congenital amegakaryocytic thrombocytopenia and thrombocytopenia with absent radii. Semin Hematol. 2006;43(3):196-203

36. Sola-Visner M. Platelets in the neonatal period: developmental differences in platelet production, function, and hemostasis and the potential impact of therapies. Hematology Am Soc Hematol Educ Program. 2012;2012:506-511.

37. Lorenz V, Ramsey H, Liu ZJ, et al. Developmental stage-specific manifestations of absent TPO/c-MPL signalling in newborn mice. Thromb Haemost. 2017;117(12):23222333

38. Baker-Groberg SM, Lattimore S, Recht M, McCarty OJ, Haley KM. Assessment of neonatal platelet adhesion, activation, and aggregation. J Thromb Haemost. 2016;14(4): 815-827.

39. Bunting S, Widmer R, Lipari T, et al. Normal platelets and megakayocytes are produced in vivo in the absence of thrombopoietin. Blood. 1997;90(9):3423-3429.

40. Ballmaier M, Germeshausen M, Krukemeier $\mathrm{S}$, Welte $\mathrm{K}$. Thrombopoietin is essential for the maintenance of normal hematopoiesis in humans: development of aplastic anemia in patients with congenital amegakaryocytic thrombocytopenia. Ann N Y Acad Sci. 2003;996:17-25.

41. Steinberg O, Gilad G, Dgany O, et al. Congenital amegakaryocytic thrombocytopenia-3 novel c-MPL mutations and their phenotypic correlations. J Pediatr Hemato Oncol. 2007;29(12):822-825
42. Dame C, Wolber EM, Freitag P, Hofmann D, Bartmann P, Fandrey J. Thrombopoietin gene expression in the developing human central nervous system. Brain Res Dev Brain Res. 2003;143(2):217-223.

43. Ehrenreich H, Hasselblatt M, Knerlich F, et al A hematopoietic growth factor, thrombopoietin, has a proapoptotic role in the brain. Proc Natl Acad Sci U S A. 2005;102(3):862-867.

44. Ivanova A, Wuerfel J, Zhang J, Hoffmann O Ballmaier M, Dame C. Expression pattern of the thrombopoietin receptor $(\mathrm{Mpl})$ in the murine central nervous system. BMC Dev Biol. 2010;10:77.

45. Hoffmann O, Rung O, Im AR, et al Thrombopoietin Contributes to Neuronal Damage in Experimental Bacterial Meningitis. Infect Immun. 2011;79(2):928936

46. Castro Conde JR, Martinez ED, Rodriguez RC, Rodriguez De Hoyos AL. CNS siderosis and dandy-walker variant after neonatal alloimmune thrombocytopenia. Pediatr Neurol. 2005;32(5):346-349.

47. Goto $T$, Kakita $H$, Takasu $M$, et al. A rare case of fetal extensive intracranial hemorrhage and whole-cerebral hypoplasia due to latent maternal vitamin $\mathrm{K}$ deficiency. Neonatal Perinatal Med. 2018;11(2):191 194.

48. Marszal E, Jamroz E, Pilch J, Kluczewska E, Jablecka-Deja H, Krawczyk R. Agenesis of corpus callosum: clinical description and etiology. J Child Neurol. 2000;15(6):401-405.

49. O'Keefe M, Kafil-Hussain N, Flitcroft I, Lanigan B. Ocular significance of intraventricular haemorrhage in premature infants. $\mathrm{Br}$ J Ophthalmol. 2001;85(3):357-359

50. Tsilou ET, Giri N, Weinstein S, Mueller C, Savage SA, Alter BP. Ocular and orbital manifestations of the inherited bone marrow failure syndromes: Fanconi anemia and dyskeratosis congenita. Ophthalmology. 2010;117 (3):615-622

51. Yildırım AT, Günes BT, Oymak Y, et al. Congenital amegakaryocytic thrombocytopenia: three case reports from patients with different clinical diagnoses and somatic abnormalities. Blood Coagul Fibrinolysis. 2015;26(3):337-341

52. Zlotogora J. What is the birth defect risk associated with consanguineous marriages? Am J Med Genet. 2002;109(1):70-71

53. Maserati E, Panarello C, Morerio C, et al Clonal chromosome anomalies and propensity to myeloid malignancies in congenital amegakaryocytic thrombocytopenia (OMIM 604498). Haematologica. 2008;93(8):12711273

54. Matatall KA, Jeong M, Chen S, et al. Chronic infection depletes hematopoietic stem cells through stress-induced terminal differentiation. Cell Rep. 2016;17(10):2584-2595.

55. Walne AJ, Dokal A, Plagnol V, et al. Exome sequencing identifies MPL as a causative gene in familial aplastic anemia. Haematologica. 2012:97(4):524-528.

56. Savoia A, Dufour C, Locatelli F, et al Congenital amegakaryocytic thrombocytopenia: clinical and biological consequences of five novel mutations. Haematologica. 2007;92(9):1186-1193.

57. Kohler S, Carmody L, Vasilevsky N, et al. Expansion of the human phenotype ontology (HPO) knowledge base and resources Nucleic Acids Res. 2019;47(D1):D1018 D1027. 